\title{
Packaging strategies: knowledge outlook on consumer buying behaviour
}

\author{
Lavuri Rambabu \\ Department of Business Management, Osmania University, Hyderabad, India, and \\ Ramlal Porika \\ School of Management, National Institute of Technology Warangal, Warangal, India
}

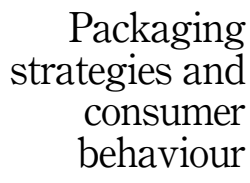

\begin{abstract}
Purpose - Packaging is a mantra for encountering a period of immense potential. It keeps on being seen as a key component in the buying decision, and also it is exhibited as a brand communication gadget that goes past the products and can interface with customers in both the physical and virtual forms. The research aspiration is to establish that the speculation of packaging approaches will influence on buyers' purchasing mode. An attempt has been made to examine and present the results. This research facilitates to discern the perception of consumer in the direction of packaging strategies and to spot the power of packaging factors, elements and strategies of product packaging on purchasing mode of buyers.

Design/methodology/approach - Data were collected from 836 respondents from the four major cities of two states in India through structure questionnaire. Every age of the respondents was targeted in the this study to get their perception and buying mode of them, and the analysis was done by using analysis of variance, correlation and regression analysis by using 23.0 version of SPSS.

Findings - The consequence of research reveals that media exposures, packaging strategies and elements have better influence on the buyers' buying mode. Business people must produce innovative bundling designs for their items to market. These allow the keeping and catching the new and existed customers, because packaging has superior influence and also helps in acquiring and retaining the new consumers for their new products.

Research limitations/implications - This study being at micro level considered that the city customers may not be similar to the rural customers. Hence, the perception of rural and urban may not be much different. A sample size is 836 drawn from the four major cities of two states in India; therefore, the sample may not represent the whole population of India. Hence, the limitation of generalization will be there. The elicited opinion of consumers may not be reliable all the times, and study considered only some of FMCG products. Originality/value - The study theme is to establish the theory as stated earlier, and it's proved consumers are considering the packaging styles and designs while purchasing the products, which promotes to meet the expectations of the present and potential customers.
\end{abstract}

Keywords Consumer perception, Consumer behaviour, Packaging elements, Packaging factors, Packaging strategies

Paper type General review

\section{Introduction}

Product packaging works as a silent salesman because customers often make a psychological association with it. Customers have environmental concerns and may pick a product packaged in reused materials. Consistently expanding purchaser awareness coupled up with competitive rivalry is presenting advertisers with a fairly remarkable test - persistent packaging

(C) Lavuri Rambabu and Ramlal Porika. Published in Journal of Industry-University Collaboration. Published by Emerald Publishing Limited. This article is published under the Creative Commons Attribution (CCBY 4.0) licence. Anyone may reproduce, distribute, translate and create derivative works of this article (for both commercial and non-commercial purposes), subject to full attribution to the original publication and authors. The full terms of this licence may be seen at http://creativecommons. org/licences/by/4.0/legalcode

I am thankful for the prior contributions as references of the journals for their amazingly valuable proposals to improve the nature of the research for carrying out this task.

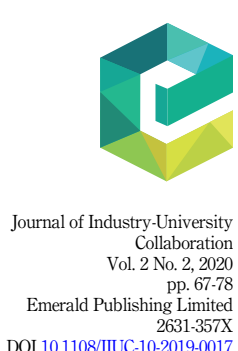

DOI 10.1108/JIUC-10-2019-0017 
JIUC

2,2

68

advancement. In the market, $90 \%$ of the customers purchase a product before checking background. Customers are stressing an extra enthusiasm for every rupee that they put in for an object. Packaging is one of the keys to the publication of attractive images, colours, symbols, articles and emblems have at a distance been the most intensive and important shipment linked between consumers and the brand owners. The Indian FMCG marketplace is relied upon to greater than twofold to $\$ 104$ billion via 2020 from the prevailing $\$ 49$ billion. The adaptable bundling industry in India is evaluated at \$12-15 billion (out of the complete bundling commercial enterprise quarter of $\$ 30-35$ billion) and is growing $15-17 \%$ in keeping with annum. The enlargement price is altogether equipped to boost up to nearly $20 \%$ for the period of a couple of years from now. Packaging item has developed to be an enterprise-promoting device for agencies in an uncommonly forceful commercial middle. The buying conduct of customers furthermore enlivened via amazing bundling, colour, wrapper and various highlights. It improves income, industrial centre quantity and brings down the prices of publicizing and showcasing and advancement. As indicated by (Rundh, 2005), the percent draws in the attention of customers greater like a specific whole upward thrust of their picture and invigorates the view of the customer around the object. Similarly, bundling passes on uncommon price to object (Underwood, 2003; Silayoi and Speece, 2007); it in reality fills in as partner affirmation equipment for separation and enables clients to determine the item from an extensive scope of parallel objects. A modern examination proposes on unmistakable components of bundling, and there has been an effect on supporter shopping performance (Ampuero and Vila, 2006; Bloch, 1995). Additionally, a couple of experts inspect the effect of bundling towards alternatives on client's entire purchase name although some others - on every development towards way of clients.

\section{Current review of literature}

Packaging requires excellent materials, use of the item and safety precautions and requires unique skills, such as attractive colours, graphics and photographs, to increase the quality of the product. Packaging is a marketing method that allows FMCG inventories to be branded in competitive markets. Routine Packaging is a systematic system for distributing products without problem and without redundancy (Sudha and Neeta, 2014). Packaging is one of the main components of pricing, structuring and promotion. A lot of shoppers would find a genuine, floor-breaking package and raise people's expectations about purchasing items. Nice quality packaging with a great place in the mind of the consumer. It remains in the minds of customers along those lines that buyers want to look for the item even as a purchase, thus bundling forward self. The importance of packaging design as a tool for communication and branding is that of competitive markets for packaged food products. Visual package elements play a key role, representing the product for many consumers, especially with a low level of involvement and haste. Most consumers have shown that they use label information, but would like it to be simpler (Silayoi and Speece, 2004). A look at (Saeed et al., 2013) reveals that customers purchase more products after looking at a well branded product and that labeling has a direct effect on the consumer's purchasing behaviour; Behzad, (2014) shows that packaging and the position of various mediating factors, such as graphics, design and color, contribute to the success of branding and marketing; and Color is ubiquitous and a source of mediation; Individuals will be able to decide between 62-90 percent of the test is based on colors in 90 seconds from their initial contact with either person or product. The intentional use of colors can also not only help to differentiate products from rivals, but can also influence moods and emotions-healthy, optimistic or negative-and thus help to increase or decrease the desire for colours, enhance mood, calm customers and reduce the time of awakening, among other things (Singh, 2006). Color affects customers' attitudes, feelings and behaviours. Advertisers must always take note of colors so that customers can perceive their products emotionally and physically (Labrecque and Saint Patrick, 2013). In this way, the business must be constantly engaged at the same time 
as the packaging coloring in order to have an effect on the customer's shopping activities and (Thomas, 2011) states that the packaging materials and wrappers on the territory contain giant elements in the packaging of the item; as the extra portion of the customer did not buy the goods due to the frightening packaging of the cloth. Thus, the packaging materials and wrappers are exquisitely excellent and thus have an effect on the selling of items. Baik et al. (2011) has explained that if a company designs an over - the-counter product with advanced factors and an excellent labeling effect on consumers who shop for practice, it may aim to achieve the highest magnificence. Since the most desirable people are those cantered consumers who might be more conscious of their self-within society and, for that reason, want to be more vigilant on a regular basis when selecting any symbol or product. Noorani and Kodandarama Setty (2007) take a look at the research that manufacturers can make the right modifications to innovative packaging designs, enable the customer to complete the specifications and discriminate against rivals in the industry. Product innovation is concerned with a number of core elements for enhancing efficiency and quality. Because each person wants something new after a high quality time, and for that reason, companies typically retain changes in their packaging strategies and product types, colours, and flavours, in order to draw customers to the individual as a whole and to take a look at what has been accomplished (Rundh, 2005) describes the overall proportions and aims of and provides elegant promotions.

\section{Objectives and hypothesis}

The research hypotheses are framed from the objectives of the study. In accordance with the research framework and the priori associations developed by studies, hypotheses are developed to be examined in this study.

(1) To evaluate effect of packaging factors by the demographic of the respondents.

(2) To study the types of media exposure that influence on buying behaviour of consumers.

(3) To assess the effect of packaging elements of the purchasing mode of buyers.

(4) To appraise packaging strategies' effectiveness towards creating a purchasing mode of consumer.

(5) To inspect the buyer's perception towards packaging strategies of products.

H1. There is no significant influence of media exposure on consumer purchase behaviour towards packaging of products.

H2. There is no significant effect of packaging factors on consumer buying behaviour.

H3. There is no significant impact of packaging elements on consumer in the case of buying behaviour.

H4. There is no significant difference in consumer perception with packaging strategies.

H5. There is no significant impact of packaging strategies on consumers' buying behaviour.

\section{Research gap, significance and framework}

From the scene, various investigations of the literature review and framed conceptualization are performed by the scholars. They are focussing mainly on the packaging terms and their performance. Only some of the studies are about the strategies for the role of the packaging in the

\section{Packaging strategies and consumer behaviour}


JIUC

2,2

70

changed competitive situation of the market in the Indian markets. The present study is mainly focussing on to evaluate the effect of packaging factors and elements on consumer buying mode towards their selected items in the market and also focusses on consumer perception regarding packaging strategies. Which have been implemented? Furthermore, what are the procedures conducted by the marketer to impact the purchaser buying behaviour with the item packaging.

With the end goal of the present examination, packaging is be conceptualized as it includes advancing, securing and upgrading the product. Packaging advances the items by pulling into consideration. The principal limited time assignment of the packaging is to pull in consideration. Since discernment is particular, the bundle ought to be intended to draw in consideration in an outwardly jumbled condition and educate the purchaser. Packaging's add to the moment acknowledgment of brand and induce the purchaser to get it. The bundle imparts more to the buyer than the real item, at the purpose of procurement where the customer chooses. The Packaging must pass on the privilege of enthusiastic characteristics about the products that it fills the customer's need. It was having a greater role to influence the consumers by image, information, characteristics and advantages of the product. Product packaging is one of the strategies of every organization, as an internal strategy to increase long-term sales. Because, most of the customers acquiring and condemning the product by its packaging configuration before buying.

\section{Materials and methods}

Myers' (1999) research is a strategic blueprint of investigation for new innovation; it explores that collecting and analysing data from the fundamental postulation. This section involves the discussion on the data working for the study.

\subsection{Participants and procedure}

The present study adopts analytical research design. Four major cities were selected from two newly formed states in India for the collection of the research data; those cities were Secunderabad and Hyderabad from Telangana state and Vijayawada and Amravati from Andhra Pradesh in India. The scope of the research study is limited to four cities of two states in India only.

\subsection{Tools and data collections}

Keeping in view on research objectives, the proper survey toll was drafted for the respondents. A structured and closed-ended questionnaire was prepared and distributed among the respondents for capturing their responses pertaining to variable of the packaging strategies. The questionnaire was finalized after pre-test. The research questionnaire has two parts of the structure. In that, major five questions related to the demographic profile of the respondents were considered in the first part; and the second part was made up of 26 questions distributed between four variables. Five questions were framed to know the influence of the media exposure on respondents about packaging, five questions were included to assess the perception of the respondents regarding packaging strategies, six questions were aimed to understand the impact of packaging factors and 10 questions for assuming the effects of the elements towards consumer buying mode. Each question measured different perception regarding the variable of packaging strategies. Researchers used five-point Likert scale for measuring the consumer response rate regarding four variables of the study and the scale in the range of 1 (strongly disagree); 2 (disagree); 3 (neutral); 4 (agree); and 5 (strongly agree). A survey was undertaken during the months of August 2018-April 2019. Data collection was started from the second week of August 2018. The data collection was over by the end of December 2018. Overall, 892 questionnaires were distributed to the sample respondents under the convenience sampling 
method; we were able to receive feedback from $93 \%$ (836) of the respondents from the four cities of two states (Table 1).

\subsection{Statistical tools used}

The following tools were applied for analysis; analysis of variance has been used to identify the mean difference in the group means in the sample. Pearson correlation used finds the linear association among selected variables and multiple regressions explore the relationship between the independent and dependent variables. For the analysis, prospective, researcher has used 23.0 version SPSS package; MS excel for tables and edit derived data from the output of SPSS.

\subsection{Demographic profile of respondents}

Table 2 discloses that the profile of the respondents from the selected sample size and profile reveals about the gender, income level, occupation status, educational profile and age of the respondents in the research study.

\begin{tabular}{|c|c|c|c|c|c|c|}
\hline S.No & Cities & State & Sample & Useable returns & Percentage rate $\%$ & \\
\hline 1 & Secunderabad & Telangana & 223 & 212 & 95 & \\
\hline 2 & Hyderabad & Telangana & 223 & 214 & 95 & \\
\hline 3 & Vijayawada & Andhra Pradesh & 223 & 211 & 94 & Table 1. \\
\hline \multirow[t]{2}{*}{4} & Amravati & Andhra Pradesh & 223 & 199 & 89 & Sample and \\
\hline & Total & & 892 & 836 & 93 & response rate \\
\hline
\end{tabular}

\begin{tabular}{|c|c|c|c|c|}
\hline Particulars & Classification & No of Responses & $\%$ & \\
\hline \multirow[t]{5}{*}{ Age (in years) } & Below 22 & 183 & 21.9 & \\
\hline & $23-32$ & 237 & 28.3 & \\
\hline & $33-42$ & 233 & 27.9 & \\
\hline & $43-52$ & 137 & 16.4 & \\
\hline & 53 and above & 46 & 5.5 & \\
\hline \multirow[t]{2}{*}{ Gender } & Male & 589 & 70.5 & \\
\hline & Female & 247 & 29.5 & \\
\hline \multirow[t]{5}{*}{ Education } & Matriculation & 76 & 9.1 & \\
\hline & $10+2$ & 112 & 13.4 & \\
\hline & Graduation & 230 & 27.5 & \\
\hline & Post-graduation & 275 & 32.9 & \\
\hline & Above PG & 143 & 17.1 & \\
\hline \multirow[t]{5}{*}{ Occupation } & Govt. employee & 255 & 30.5 & \\
\hline & Private employee & 306 & 36.6 & \\
\hline & Business & 99 & 11.8 & \\
\hline & Homemaker & 84 & 10.0 & \\
\hline & Student & 92 & 11.0 & \\
\hline \multirow[t]{5}{*}{ Monthly income (in rupees) } & Below 20,000 & 90 & 10.8 & \\
\hline & $20,001-30,000$ & 128 & 15.3 & \\
\hline & $30.001-40,000$ & 321 & 38.4 & Table 2. \\
\hline & $40,001-50,000$ & 204 & 24.4 & Demographic statistics \\
\hline & 50,001 & 93 & 11.1 & of respondents \\
\hline Total & & $n=836$ & $100 \%$ & $(n=836)$ \\
\hline
\end{tabular}


JIUC

2,2

72

Desk 2 discloses respondent's demographic statistics, participants were grouped into five groups by their age groups. The results reveal that $28.3 \%$ candidates belong to the age group of 23-32 years, 233 participants with $27.9 \%$ contribution belong to 33-42 years and least $5 \%$ of them were 53 and above; $5.5 \%$ of the respondents were 51 and above years. Male and female were not in equal proportion in the sample, $70.5 \%$ of the whole respondents were male accompanied by $29.5 \%$ of females. As far as education profile of respondents is concerned, most of the respondents had attained education post-graduation (32.9\%), and followed by $27.5 \%, 17.1 \%, 13.4 \%$ and $9.1 \%$ belonging to Graduation, above $\mathrm{PG}$ and $10+2$ and Matriculation, respectively. As far as occupational profile is concerned, more than $36.6 \%$ of the respondents are working as private employees, and it is observed that $30.5 \%, 11.8 \%$, $11.0 \%$ and $10.0 \%$ are working as govt. employees, business people, students and homemakers. It is evident that the monthly income of the majority of the respondents, $38.4 \%$ of families, was between 30,001 and 40,000 followed by $24.4 \%, 15.3 \%, 11.1 \%$ and $10.8 \%$ with the income of 40,001-50,000, 20,001-30,000 and 50,001 and above and below 20,000.

\section{Consequences and discussions}

Before the test hypothesis, there is need to examine the reliability and validity test for research data with the help of Cronbach's alpha test; it measures the internal consistency for all dimensions of research data; minimum acceptable alpha score is above 0.70 (Aderson and Gerbing, 1988). This confirms the validity and reliability of present study. Major variables: media exposure, consumer perception, packaging factors and packaging elements of client notion are considered. Alpha values were calculated one after the other for each variable for measuring variables' validity and reliability. Cronbach's alpha values for media exposure, consumer perception, packaging factors, packaging elements and packaging strategies are observed to be $0.757,0.780,0.844,0.802$ and 0.811 . The result values disclose all variable research data have good validity and reliability. So, this data is helpful and could be used for research hypothesis testing (Table 3).

\subsection{Results of ANOVAs}

It's a statistical tool used for the analysis of the difference among group means in a sample by using $F$-distribution. Results are given in the following tables.

\subsubsection{Media exposure influence on purchase behaviour of respondents}

H1. There is no significant influence of media exposure on consumer purchase behaviour towards packaging of products.

The results of one-way ANOVAs are given disk 4, the results show that the media exposures have significant influence on buyers' behaviour and value of $F$ distribution is 80.622 and statistically significant value is 0.001 , since the statistical significance value is $<0.05$. Hence, it's smaller than the $p$-value. Subsequently, given statement is strongly rejected. This

\begin{tabular}{lcc}
\hline Questionnaire & Items & Alpha \\
\hline Media exposure & 5 Items & 0.757 \\
Consumer perception & 5 Items & 0.780 \\
Packaging factors & 6 Items & 0.844 \\
Packaging elements & 10 Items & 0.802 \\
Packaging strategies & 16 Items & 0.811
\end{tabular}

Table 3.

Packaging strategies

16 Items

0.802

Note(s): Packaging strategies: Packaging elements and packaging factors 
evidence reveals that media exposure has great influence on buyers motivating them to purchase the products (see Table 4).

\subsubsection{Affect packaging factors in purchasing mode of consumers}

H2. There is no significant effect of packaging factors on consumer buying behaviour.

The desk reveals the results of ANOVAs. It shows that packaging factors $f$-statistical value is 92.762 and statistical significance assessment is smaller than significance value. The final outcome is null hypothesis rejected. Finally, packaging factors have better effect on buying mode of consumers (Table 5).

\subsubsection{Impact of packaging elements towards purchasing actions of clients}

H3. There is no significant impact of packaging elements on consumer in the case of buying behaviour.

Table 6 reveals that $f$-distribution value is 53.248 and the value of sig. is zero $(p<0.05)$. The results explore that the null hypothesis $(\mathrm{H} 3)$ statement is strongly rejected and statement of alternative hypothesis accepted. Packaging elements have an impact on the buyers' purchasing actions.

\subsubsection{Consumer perception towards packaging strategies}

H4. There is no significant difference in consumer perception with packaging strategies.

Table 7 reveals that the consumer perception $F$-value is 40.170 and its significance value is 0.000 which is smaller than the significance value $(\phi<0.05)$. This is indicating that the mean difference in consumer perception regarding strategies of packaging is statistically significant. So, alternative hypothesis accepted and the null hypothesis is strongly rejected.

6.1.5 Packaging strategies impact on the buyer's behaviour mode

H5. There is no significant impact of packaging strategies on consumers' buying behaviour.

The box reveals that 38.127 is the variance between groups and 42.031 is the variance within the groups and followed by the value of the $F$-distribution is 105.873 and its significance value

\begin{tabular}{lcccrr}
\hline & Sum of square & df & Mean square & $f$ & Sig \\
\hline Between groups & 56.074 & 7 & 8.011 & 80.622 & 0.001 \\
Within groups & 81.177 & 807 & 0.099 & & \\
Total & 137.251 & 824 & & &
\end{tabular}

Packaging strategies and consumer behaviour

\begin{tabular}{|c|c|c|c|c|c|c|}
\hline & Sum of squares & $\mathrm{df}$ & Mean square & $F$ & Sig & \\
\hline Between groups & 41.211 & 5 & 8.243 & 92.762 & 0.000 & \\
\hline Within groups & 72.814 & 819 & 0.089 & & & Table 5 \\
\hline Total & 93.194 & 824 & & & & Results of ANOVAs \\
\hline
\end{tabular}

\begin{tabular}{lcccrr}
\hline & Sum of squares & df & Mean square & $f$ & Sig \\
\hline Between groups & 29.197 & 7 & 4.171 & 53.248 & 0.000 \\
Within groups & 63.997 & 807 & 0.078 & & \\
Total & 93.194 & 824 & & &
\end{tabular}


JIUC 2,2

74

Table 7.

Results of ANOVAs between consumer perception and packaging strategies is 0.001 . Thus, the result discloses that best innovative product strategies have more influence towards buyers' purchasing mode and also fulfil requirements of clients (Table 8).

\subsection{Pearson correlation test results}

Pearson correlation test is helpful to identify the linear relationship between the selected variables and it has values from +1 to -1 ; here +1 value indicates perfect correlation, -1 value reveals negative correlation and 0 value implies no correlation. The numerical values of correlation coefficient reflect the degree of relation between variables. Pearson correlation results reveal in the following disks 7, 8, 9 and 10 .

Desk 9 discloses the association between media exposure and buying mode of respondents; selected exposure variables such as television $\left(r=0.567^{* * *}\right)$, newspaper and magazine $\left(r=0.515^{* *}\right)$ are having strongly associated with the consumer purchase behaviour at the $1 \%$ significance level, whereas outdoor $\left(r=-0.471^{* *}\right)$ and Internet $\left(r=-0.425^{* *}\right)$ having $a$ negative and $a$ weak correlation with buying mode of consumers at the $1 \%$ significance level. Radio $\left(r=0.310^{* * *}\right)$ having weak correlation with the consumer buying mode at the $1 \%$ significance level (Table 9).

Packaging factors such as product safety (PF1) $\left(r=0.590^{*}\right)$, good-quality packaging (PF5) $\left(r=0.575^{* *}\right)$ and appearance (PF2) $\left(r=0.526^{* * *}\right)$ are having strong relations between factors of packaging and purchasing mode at the 0.01 significance levels, and factors such as sachet packaging (PF4) $\left(r=-0.302^{* *}\right)$ are having negative associations with consumer buying behaviour at the 0.01 significance level (Table 10).

Desk 11, the Pearson technique result shows association between elements of packaging such as printed information and buying action of the consumer $\left(r=0.612^{* * *}\right)$ and colour of packaging $\left(r=0.542^{* *}\right)$ at 0.01 significance levels, and desk also reveals the weak relationship between elements and consumer buying action; followed by the background image of the packaging having a weak relationship with the consumer $\left(r=0.405^{* * *}\right)$ at $1 \%$ of significance level (Table 11).

\begin{tabular}{lccccr}
\hline & Sum of square & df & Mean square & $F$ & Sig \\
\hline Between groups & 19.850 & 12 & 1.654 & 40.170 & 0.000 \\
Within groups & 33.437 & 812 & 0.041 & & \\
Total & 53.287 & 824 & & & \\
\hline
\end{tabular}

\begin{tabular}{lcrccr}
\hline & Sum of square & Df & Mean square & $F$ & Sig \\
\hline Between groups & 38.127 & 7 & 5.447 & 105.873 & 0.001 \\
Within groups & 42.031 & 807 & 0.051 & & \\
Total & 80.158 & 824 & & & \\
\hline
\end{tabular}

Table 8.

Results of ANOVAs

Within groups

42.031

824

\begin{tabular}{llc}
\hline S.No & Media exposure & Pearson correlations $(r)$ \\
\hline 1 & TV & $0.567^{* *}$ \\
2 & Radio & $0.310^{* *}$ \\
3 & Newspaper and Magazine & $0.515^{* *}$ \\
4 & Outdoor & $-0.471^{* *}$ \\
5 & Internet & $-0.425^{* *}$
\end{tabular}

Note(s): Significance level of correlation at 1\% (two-tailed): ** 
Pearson technique numerical value reflects the degree of association among consumer perception and packaging strategies, from the above disk, the result discloses good association among the packaging keeps items fresh and hygienic (CP1) and packaging strategies with $r=0.546^{* *}$ at the $5 \%$ significance level and CP4 and PPS having a good correlation with $r=0.524^{* *}$, but CP3 $r=-0.475^{* *}$ having $a$ negative correlation with PPS at the $5 \%$ significance level (Table 12 ).

\subsection{Results of multiple regressions}

It clarifies the connection among independent and dependent factors, and it's supportive for recognizing quality impact of independent and dependent factors, it forecasts impact and changes and it predicts the future qualities. Following table demonstrates the development of the speculation of the hypothesis framework.

The results of multiple regression analysis with supporting five developed models evolved to evaluate the association among the predictors and structured variables. Through

\begin{tabular}{llr}
\hline S.No & Packaging factors & Pearson correlations $(r)$ \\
\hline 1 & Product safety (PF1) & $0.590^{* *}$ \\
2 & Appearance (PF2) & $0.526^{* *}$ \\
3 & Easy conveyance (PF3) & $0.416^{* *}$ \\
4 & Sachet packaging (PF4) & $-0.302^{* *}$ \\
5 & Good-quality packaging (PF5) & $0.575^{* *}$ \\
6 & Eco-friendly packaging (PF6) & $0.491^{* *}$
\end{tabular}

\section{Packaging strategies and consumer behaviour}

Table 10.

Results of correlations between the packaging factors and buying behaviour

\begin{tabular}{llrr}
\hline S.No & Packaging elements & Pearson correlations $(r)$ & \\
\hline 1 & Colour of packaging & $0.542^{* *}$ & \\
2 & Back ground image of packaging & $0.405^{* *}$ \\
3 & Materials of packaging & $0.457^{* *}$ & $0.612^{* *}$ \\
4 & Printed information & $0.484^{* *}$ & \\
5 & Innovation of packaging & $0.411^{* *}$ & Table 11. \\
6 & Label of packaging & $0.513^{* *}$ & $0.473^{* *}$ \\
7 & Quality of packaging & $0.412^{* *}$ & Results of correlations \\
8 & Design of packaging & $0.443^{* *}$ & between the packaging \\
9 & Language used on packaging & & elements and buying \\
10 & Brand image on the packaging & & \\
Note(s): Significance level of correlation at 1\% (two-tailed): $* *$ & &
\end{tabular}

S.No Consumer perception elements

\begin{tabular}{llr}
\hline 1 & Packaging keeps items fresh and hygienic (CP1) & $0.546^{* *}$ \\
2 & Packaging makes convenient to use the products (CP2) & $-0.475^{* *}$ \\
3 & With the help of packaging, items will be available in different sizes based on & $0.471^{* *}$ \\
& the requirements (CP3) & $0.524^{* *}$ \\
4 & Packaging communicates proper information (CP4) & $0.492^{* *}$ \\
5 & Packaging makes an attention by the attracting consumers (CP5) &
\end{tabular}
(r)

Pearson correlations 

JIUC
2,2

76

the table, all the regression models' $F$-values are statistically significant; the percentage value of $R^{2}$ reveals variance among the selected variables in this analysis.

The Model-1 indicates that exposure of media vehicle has better influence on consumer behaviour, because of media exposure maintaining good information about packaging, and it helps to give good perceived information to target customers $(\beta=0.311, p \leq 0.001)$, with $32.3 \%$ of variance explained by the independent factors. So hypothesis Ha1 is supported and Ho1 rejected. It is observed from the model-2 factors of packaging affect consumer purchasing mode greatly, and it helps to attract and grab their attention by best innovatively $(\beta=0.429$, $p \leq 0.001$ ) and $54.2 \%$ of the variance, this hypothesis $\mathrm{Ha} 2$ is also supported. Followed $b y$, the model-3, packaging elements having greater influence on buying mode $(\beta=0.572, p \leq 0.001)$ which explains $68.7 \%$ of variance by predictors, so Ha3 hypothesis is supported, and the model-4, most of the consumer having $a$ positive perception towards packaging strategies $(\beta=0.492, p \leq 0.001)$ and $49.2 \%$ variance explained by the predictors on the dependent factors. Final model-5 indicates that packaging strategies are having $a$ positive impact on the consumer $(\beta=0.537, p \leq 0.001)$ which explains $64.1 \%$ of variance in the dependent factors by the predictors. Thus Ha5 hypothesis supported and the null hypothesis is rejected. The data disclose that strategy of packaging impacts more on the buyers' purchasing mode (Table 13).

\section{Research recommendations}

\subsection{In-depth research towards innovative packaging}

Most of the customers want variety of options of the products while choosing the product based on the packaging. Hence, the marketer should focus on the innovative and unique packaging, with distinctive different size, instruction, convenience, right shape and style of the product, while comparing with the competitors in the market segmentation.

\subsection{Effective communication through packaging}

Product packaging is acting as a great communication tool for the target audience and their awareness levels gradually increasing. Packaging must communicate about the product and brand relevant information, composition of ingredients, purpose and quality. Packaging should also have all such information in regional languages to respect customers.

\subsection{Packaging acts as promotional tool}

The significance of effective packaging is not restricted to the storage and protection of products, and it has great significance to create attention and make an action to purchase the product.

\subsection{Eco-friendly packaging}

Eco-friendly packaging has greater significance nowadays. Thus, the marketers should concentrate on this aspect and should use best practices to the possible extent, thereby the use of eco-friendly packaging, and it should be recyclable.

Table 13.

Summary results of multiple regressions

\begin{tabular}{lccccc}
\hline Independent factors & Media \\
Model & $\begin{array}{c}\text { Packaging } \\
\text { exposure (1) }\end{array}$ & Packaging & $\begin{array}{c}\text { Packaging } \\
\text { strategies (4) }\end{array}$ & $\begin{array}{c}\text { Consumer } \\
\text { perception (5) }\end{array}$ \\
\hline$R^{2}$ & 0.323 & 0.687 & 0.542 & 0.641 & 0.659 \\
$B$ & $0.311^{* * *}$ & $0.572^{* * *}$ & $0.429^{* * *}$ & $0.537^{* * *}$ & $0.492^{* * * *}$ \\
$F$-value $\quad 46.129$ & 76.104 & 55.438 & 83.435 & 98.133 \\
Dependent factor: buying behaviour of consumers & & & \\
Note(s): $* * *<0.001, * *>0.001$ & & & \\
\hline
\end{tabular}


Mass media playing an important role to influence the customers' purchasing behaviour. For this, marketers maintain high quality of video, audio, clarity of message about product packaging. It is must and vary in different segments.

\section{Limitations and direction for further research}

This study is at micro level and considered that the city customers may not be similar to the rural customers. Hence, the perception of rural and urban may not be much different. A sample size of 836 was drawn from the four major cities of two states in India; therefore, the sample may not represent the whole population of India. Hence, the limitation of generalization will be there. The elicited opinion of consumers may not be reliable all the times, due to individual bias, differences in age, gender, education levels, attitude, income, profession and so on. This study did not consider all the FMCGs. Since few categories in FMCG products are considered, such as personal care products (cosmetics), dairy products (milk, ghee, ice cream), food products (biscuits, bread, cakes) and beverages (soft drinks and energy drinks) and only to evaluate the packaging strategies' impact on the purchase behaviour of final selected respondents, and individual tendency of respondents may also have inclined outcomes imperceptibly while tending to the examination, despite the fact that endeavours were made to show outcomes all through a broad range of quantitative and emotional concerns.

The studies can be made further exhaustive by including rural and different socioeconomic demographics. This study may be extended with large sample and both rural and urban segments covering. An observation technique of study may be considered consecutive to capture the consumer's natural behaviour in the retail outlets. As the present study is limited to the FMCG goods, however, a single product may be considered for in-depth study on the packaging strategies.

\section{Conclusions}

During the previous decade, the universe of packaging has seen numerous innovations and designs; it has assumed a strategic role in the product life cycle. The study endeavoured to investigate the packaging strategies impact on the acquiring consumer behaviour and attempt to comprehend its influence in the purchase decision-making. Respondents as initiators, information seekers, influences, decides, buyers and actual users play a greater role in modern packaging is not viewed as just a box/container or outer covering, but packaging has various tasks to play. Customer perception and intention get changed day by day, and hence, the marketers should take immediate initiation to provide easy-to-use products/userfriendly, recyclable, conservative and innovative product packaging options. Customers need the product packaging in various shapes, sizes, colours, because the customers are becoming more conscious and demanding. The various types of product packaging strategies impact on purchase behaviour of customers. The packaging is viewed as an essential to fulfil the basic need of the consumers, and it should always be one step forward to consumer necessities and competitors. The study concludes that the customer's perceptions towards packaging products are highly influential to the strategies being adopted by the marketers in influencing and ensuring consumer buying behaviour and patrons, through select packaging strategies, such mass media exposure, innovative packaging strategies and other elements. Packaging strategies have significant impact on buying intentions and behaviour according to the study.

\section{References}

Aderson, J.C. and Gerbing, D.W. (1988), "Structural equation modelling in practice: a review and recommended two steps approach", Psychological Bulletin, Vol. 103 No. 3, p. 411.

\section{Packaging strategies and consumer behaviour}


Ampureo, O. and Vila, N. (2006), "Consumer perception of product packaging”, Journal of Consumer Marketing, Vol. 23 No. 2, pp. 100-112.

Baik, M., Suk, H., Suh, T. and Kim, Y. (2011), "Organic food package design management in SMEs", Proceedings of IASDR2011, 4th World Conference on Design Research held at Delft, Netherlands.

Behzad, M. (2014), "An Art of packaging: an investigation into the role of color in packaging, marketing and branding", International Journal of Organizational Leadership, Vol. 3 No. 1, pp. 92-102.

Bloach, P. (1995), "Seeking the ideal from: product design and consumer response", Journal of Marketing, Vol. 59 No. 6, pp. 16-29.

Labrecque, L., Patrick, V. and Milne, G. (2013), "The marketers prismatic palette: a review of color research and future direction”, Psychology and Marketing, Vol. 30, No. 2, pp. 187-202.

Myers, R.H. (1999), "Response surface methodology-current status and future directions", Journal of Quality Technology, Vol. 31 No. 1, pp. 30-44.

Noorani, H. and Kodandarama Setty, M. (2007), "Three steps for successful implementation of sale portals in CPG companies", International Journal of Retail and Distribution Management, Vol. 35 No. 9, pp. 746-749.

Rundh, B. (2005), “The multi-faced dimension of packaging. Marketing logistic or marketing tool?", British Food Journal, Vol. 107 No. 9, pp. 670-684.

Saeed, R., Lodhi, R.N., Rauf, A., Rana, M.I., Mahmood, Z. and Ahmed, N. (2013), "Impact of labelling on consumer buying behaviour in sahiwal, Pakistan", World Applied Science Journal, Vol. 24 No. 9 , pp. 1250-1254.

Silayoi, P. and Speece, M. (2004), "Packaging and purchasing decisions; an exploratory study on the impact of involvement level and time pressure", British Food Journal, Vol. 106 No. 8, pp. 607-628.

Silayoi, P. and Speece, M. (2007), "The importance of packaging attributes: a conjoint analysis approach", European Journal of Marketing, Vol. 41 Nos 11-12, pp. 1495-1517.

Singh, S. (2006), "Impact of color on marketing”, Management Decision, Vol. 44 No. 6, pp. 783-789.

Sudha, R. and Neeta, S. (2014), "Packaging and fast moving consumer goods with special reference to shampoos in rural perspectives", International Journal of Enhanced Research in Educational Development, Vol. 2 No. 5, pp. 16-20.

Thomas, S. (2011), "Effects of packaging design on consumer expectations of food product healthiness", Aarhus School Of Business, Department of Marketing and Statistics, pp. 5-6.

Underwood, R. (2003), "The communicative power of product packaging: creating brand identity via lived and mediated experience", Journal of Marketing Theory and Practice, Vol. 11 No. 1, pp. 62-76.

\section{Corresponding author}

Lavuri Rambabu can be contacted at: rambabu.lavuri@gmail.com

For instructions on how to order reprints of this article, please visit our website:

www.emeraldgrouppublishing.com/licensing/reprints.htm

Or contact us for further details: permissions@emeraldinsight.com 